\title{
Abnormal Iron Deposition in Renal Cells in the Rat with Chronic Angiotensin II Administration
}

\author{
Nobukazu Ishizaka, Toru Aizawa, Ieharu Yamazaki, Shin-ichi Usui, Ichiro Mori, \\ Kiyoshi Kurokawa, Shiow-Shih Tang, Julie R. Ingelfinger, Minoru Ohno, and \\ Ryozo Nagai
}

\begin{abstract}
Department of Cardiovascular Medicine (NI, TA, SU, MO, RN), University of Tokyo Graduate School of Medicine, Tokyo, and Department of Pathology (IM), Wakayama Medical College, Wakayama, Department of Pathology (IY), Inoue Memorial Hospital, Inoue, and Department of Medicine (KK), Tokai University School of Medicine, Tokai, Japan; and Pediatric Nephrology Laboratory, Massachusetts General Hospital, Harvard Medical School (S-ST, JRI), Boston, Massachusetts
\end{abstract}

SUMMARY: Acute experimental iron loading causes iron to accumulate in the renal tissue. The accumulation of iron may play a role in enhancing oxidant-induced tubular injury by producing increased amounts of reactive oxygen species. From findings in cells from heme oxygenase-1 (HO-1)-deficient mice, $\mathrm{HO}-1$ is postulated to prevent abnormal intracellular iron accumulation. Recently, it has been reported that $\mathrm{HO}-1$ is induced in the renal tubular epithelial cells, in which iron is deposited after iron loading, and that this HO-1 induction may be involved in ameliorating iron-induced renal toxicity. We previously showed that chronic administration of angiotensin II to rats induces HO-1 expression in the tubular epithelial cells. These observations led us to investigate whether there is a link between iron deposition and $\mathrm{HO}-1$ induction in renal tubular cells in rats undergoing angiotensin II infusion. In the present study, rats were given angiotensin II for continuously 7 days. Prussian blue staining revealed the distinct deposits of iron in the proximal tubular epithelial cells after angiotensin II administration. Electron microscopy demonstrated that iron particles were present in the lysosomes of these cells. Histologic and immunohistochemical analyses showed that stainable iron and immunoreactive ferritin and HO-1 were colocalized in the tubular epithelial cells. Treatment of angiotensin II-infused rats with an iron chelator, deferoxamine, blocked the abnormal iron deposition in kidneys and also the induced expression of $\mathrm{HO}-1$ and ferritin expression. Furthermore, deferoxamine treatment suppressed the angiotensin II-induced increase in the urinary excretion of protein and $\mathrm{N}$-acetyl- $\beta$-D-glucosaminidase, a marker of tubular injury; however, deferoxamine did not affect the angiotensin II-induced decrease in glomerular filtration rate. These results suggest that angiotensin II causes renal injury, in part, by inducing the deposition of iron in the kidney. (Lab Invest 2002, 82:87-96).

$I$

n humans and animals, repetitive or chronic exposure to heme proteins results in an abnormal deposition of iron in the kidney, which may cause morphologic and functional damage to this organ (Kawabata et al, 1997; Nath et al, 2001; Zhou et al, 1996). Although the underlying mechanism of iron overload-associated renal injury has not been fully elucidated, iron accumulation is postulated to induce renal injury, at least in part, by increasing the production of reactive oxygen species (Zainal et al, 1999; Zhou et al, 2000). Accumulation of iron has also been suggested to play a role in the renal injury in rhabdomyolysis (Nath et al, 1992), ischemic renal disease (Paller and Hedlund, 1988), and glomerulonephritis (Alfrey et al, 1989).

Received October 15, 2001.

This work was supported in part by a research grant from the Tokyo Hypertension Conference and by a research grant from the Sankyo Foundation of Life Science (NI).

Address reprint requests to: Dr. Nobukazu Ishizaka, University of Tokyo, Graduate School of Medicine, Hongo 7-3-1, Bunkyo-ku, Tokyo 113-8655, Japan.E-mail:nobuishizka-tky@umin.ac.jp
Heme oxygenase $(\mathrm{HO})$ is a rate-limiting enzyme of heme degradation that has two isoforms: an inducible form, HO-1 (Vile and Tyrrell, 1993), and a constitutive form, $\mathrm{HO}-2$. Recent data showed that $\mathrm{HO}-1$ is induced in the kidney by iron overload (Nath et al, 2001) and that $\mathrm{HO}-1$ induction ameliorates the renal injury induced by iron overload. There are at least two possible mechanisms by which $\mathrm{HO}-1$ induction acts protectively against iron-induced toxicity. First, iron accumulation may enhance oxidative tissue injury by generating highly toxic hydroxyl radicals, and $\mathrm{HO}-1$ may protect against this oxidative tissue injury (Vogt et al, 1995), in part, by generating the antioxidants biliverdin and bilirubin (Stocker et al, 1987). Second, HO-1 may play a crucial role in modulating the levels of intracellular iron, which is a pro-oxidant (Ferris et al, 1999). This notion is also supported by findings of abnormal iron deposition in the kidneys of both $\mathrm{HO}$ 1-deficient mice (Poss and Tonegawa, 1997) and a human case with HO-1 deficiency (Ohta et al, 2000).

Both iron deposition and $\mathrm{HO}-1$ induction occur in the renal tubular epithelial cells in an animal model of iron overload (Nath et al, 2001). HO-1 induction is postulated to ameliorate iron-induced renal injury 
(Nath et al, 1992). We previously showed that there is robust $\mathrm{HO}-1$ induction in the renal tubular epithelial cells in a rat model of chronic angiotensin II administration and that this induction of HO-1 may have a possible role in renoprotection (Aizawa et al, 2000, 2001). The similarity in these different animal models led us to hypothesize that there is a link between iron deposition and administration of angiotensin II. In the present study, we have investigated whether continuous angiotensin II administration is associated with iron deposition in the kidney, which in turn may have a role in the angiotensin II-induced increase in excretion of urinary protein.

\section{Results}

\section{Iron Staining of the Kidney Samples from Angiotensin II-Infused Rats}

Prussian blue staining revealed that there was essentially no iron deposition in the cortex of control rats (Fig. 1A). By contrast, distinct deposits of iron were observed in the cortical regions (Fig. 1B), but not in the medullary regions (Fig. 1C), of the angiotensin IItreated rats. Higher magnification microscopy revealed that iron deposition occurred occasionally in the cells of Bowman's capsules (Fig. 1D) and predominantly in the tubular epithelial cells (Fig. 1E). Immunoperoxidase staining for $\mathrm{HO}-1$ in the serial sections of the kidney demonstrated that tubular epithelial cells with positive iron deposition also strongly expressed HO-1 (Fig. 1F). Because HO-1 can liberate iron from heme compounds, we examined whether iron deposition in the renal tubules was a consequence of the induction of $\mathrm{HO}-1$ in these cells. For this purpose, zinc protoporphyrin IX, an $\mathrm{HO}$ inhibitor, was given to angiotensin II-infused rats. There was no apparent difference in the extent of renal iron deposition between angiotensin II-infused rats and rats given angiotensin II plus zinc protoporphyrin (Fig. 1G), suggesting that induction of $\mathrm{HO}-1$ is not critical for the iron deposition in the kidney. In addition to the Prussian blue staining (Fig. 1H), iron deposition in the tubular cells after angiotensin II infusion was confirmed by Turnbull's blue staining (Fig. 11).

\section{Electron Microscopy of the Kidney After Angiotensin II Administration}

After angiotensin II infusion, electron microscopy revealed the presence of electron-dense particles in secondary lysosomes in the tubular cells with apparent brush borders, which are most likely to be proximal tubular epithelial cells (Fig. 2, A [arrows] and B). These electron-dense particles were identified as iron particles from their characteristic crystal structure at higher magnifications (Fig. 2, C and D) and were not seen in other cell types, such as distal tubular epithelial cells, mesangial cells, and collecting duct cells, or in other intracellular structures, such as the nuclei and the mitochondria.

\section{The Plasma Iron Concentration and Blood Markers of Leakage of Intracellular Enzymes}

We examined whether chronic angiotensin II administration was associated with an increased concentration of circulating iron, and we found that plasma iron concentration was significantly higher after 7 days of angiotensin II infusion (Table 1). Next, we assessed whether angiotensin II administration evoked muscle injury by measuring plasma concentrations of lactate dehydrogenase (LDH) and creatine phosphokinase (CK), which are the markers of intracellular enzyme leakage. After angiotensin II infusion, plasma concentrations of LDH and CK showed a 3.4-fold and a 2.4-fold increase, respectively, over control values (Table 1), suggesting the presence of muscle injury. Levels of cardiac troponin T (CTnT) in the venous blood were also measured to examine whether cardiac injury had occurred. CTnT levels were not measurable in the samples from control rats; by contrast, CTnT was within the detectable range in six of the eight samples from angiotensin II-treated rats, indicating the damage of cardiomyocytes, consistent with our previous findings (Ishizaka et al, 2000). In contrast, there was no significant reduction in the level of the red blood cells, blood hemoglobin, or hematocrit (Table 1) after angiotensin II administration; thus, hemolysis did not seem to have occurred.

\section{Immunohistochemistry of Ferritin}

In previous animal models of iron overload, renal tubular cells that contained iron deposits were also positive for ferritin, a major chelator of iron that will safely sequester toxic iron. We therefore investigated the expression of ferritin in the kidneys of angiotensin II-treated rats. Immunohistochemistry revealed that ferritin was only faintly detectable in the control kidney (Fig. 4A); however, 7 days of angiotensin II infusion caused a robust increase in ferritin expression in the renal tubules but not in the medullary regions (Fig. 4, B and C). Staining of serial sections with ferritin (Fig. 4D) and Prussian blue (Fig. 4E) revealed that some of the tubular epithelial cells were positive for both immunoreactive ferritin and iron deposits. Costaining of kidney sections with immunoperoxidase for ferritin and Prussian blue provided stronger evidence for this colocalization (Fig. 4F).

\section{Regulation of Ferritin by Angiotensin II and Iron Chelator}

We investigated the regulation of renal ferritin more quantitatively by immunoblot analysis. An anti-rat ferritin antibody detected a band of approximately 25-kd size. This band disappeared when the antibody was preincubated with immunizing peptide, ie, rat liver ferritin (Fig. 5A), indicating the validity of this antibody for immunoblot analysis. In accordance with the finding of immunohistochemistry results, ferritin was only weakly expressed in the kidneys of control rats; however, after angiotensin II administration for 5 or 7 consecutive days, a robust increase in the ferritin expression was seen (Fig. 5B). 

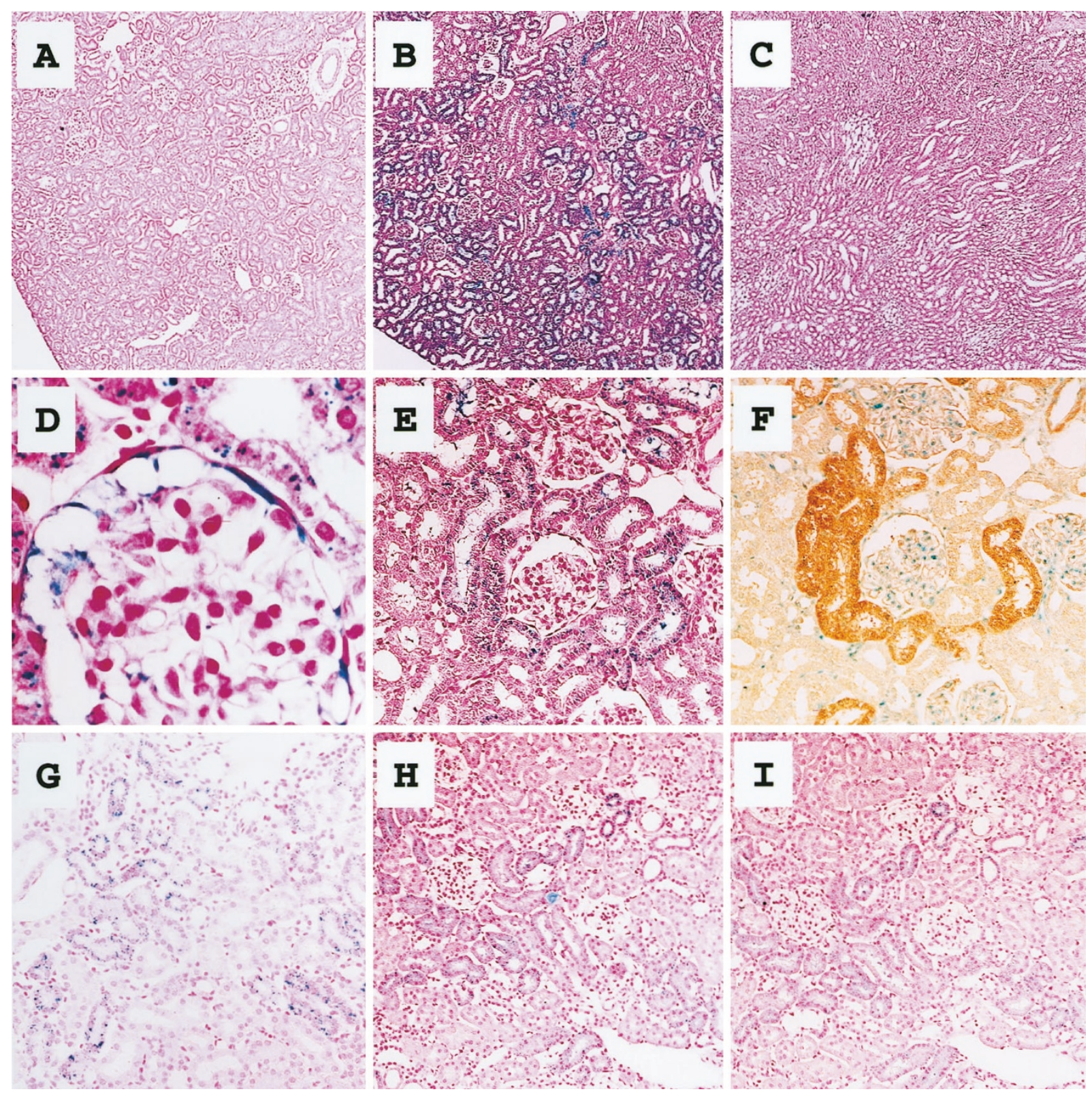

Figure 1.

Iron deposition and heme oxygenase-1 (HO-1) expression in the kidney of angiotensin II-infused and control rats. A to E, G, and $\mathrm{H}$, Prussian blue staining of iron in the kidney. F, Immunoperoxidase staining of HO-1. I. Turnbull's blue staining. Specimens were either from control rats (A) or from rats with angiotensin II infusion at a dose of $0.7 \mathrm{mg} / \mathrm{kg} /$ day for 7 days (B to I). Although no apparent iron deposition was seen in the control kidney (A), marked deposits of iron were observed in the renal cortex (B) but not in the medullary regions (C) of the kidney after angiotensin II infusion for 7 consecutive days. Iron deposits were seen occasionally in the cells of the Bowman' s capsule (D). E and F were from serial sections. Intense H0-1 staining was observed in the renal tubular epithelial cells with positive iron deposition. G, Prussian blue staining of the kidney from angiotensin II-infused rats that were given zinc protoporphyrin, an inhibitor of HO. Iron deposition in the tubular epithelial cells could still be seen. $\mathrm{H}$ and I are from serial sections. A similar pattern of iron staining was demonstrated by Prussian blue and Turnbull's blue staining. Original magnifications are $\times 100(\mathrm{~A}$ to $\mathrm{C}, \mathrm{H}, \mathrm{I}), \times 250(\mathrm{E}$ to $\mathrm{G})$, and $\times 500$ (D)

We treated the rats with angiotensin II infusion plus deferoxamine (DFO) at a dose of $6 \mathrm{mg} / \mathrm{kg} /$ day to see whether iron chelation would have any impact on the regulation of ferritin in the kidney. DFO treatment did not affect the blood pressure in either rats not treated with angiotensin II or rats undergoing angiotensin II administration for 7 days (Table 2). However, DFO completely inhibited the angiotensin II-induced increase in plasma iron concentrations and completely abolished angiotensin II-induced up-regulation of ferritin in the kidney (Fig. 5C). In addition, histologic analysis revealed that DFO treatment blocked the abnormal deposition of iron in the tubular epithelial cells in the kidneys of rats treated with angiotensin II (data not shown) and also inhibited angiotensin IIinduced $\mathrm{HO}-1$ up-regulation in the kidneys (Fig. 5D).

\section{Effect of DFO on Renal Function in Rats with Angiotensin II Infusion}

We have previously reported that chronic angiotensin II administration causes an increase in the urinary 


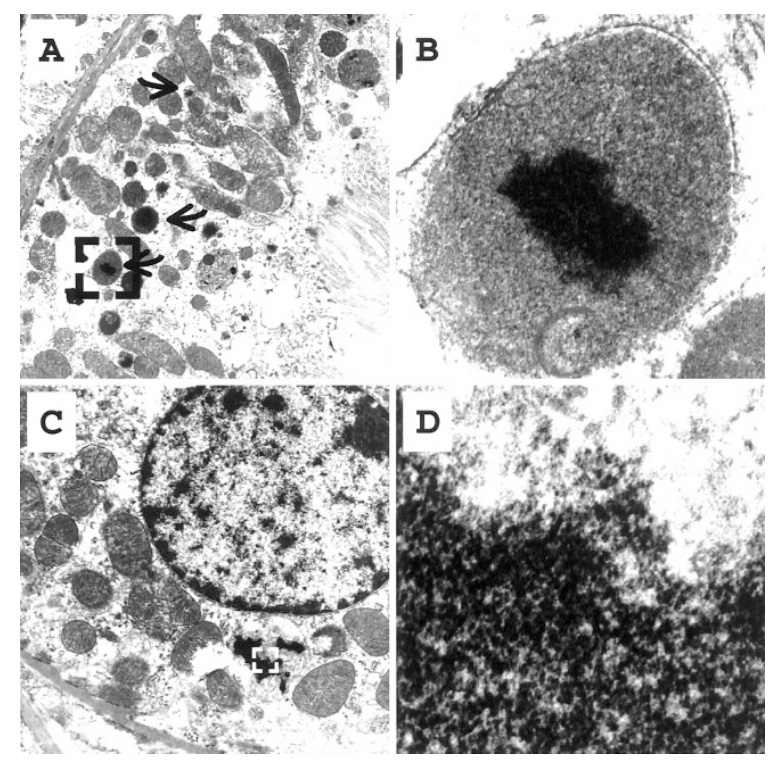

Figure 2.

Electron microscopy of the proximal tubular epithelial cells in the kidneys of angiotensin II-infused rats. A, The brush border identifies the cell as a proximal tubular epithelial cell. Several lysosomes including electron-dense particles can be seen (arrows). C, No such particles are present in either mitochondria or nuclei. $B$ and $D$, Higher-magnification images of the bracketed region in $A$ and $C$, respectively. Secondary lysosome with apparent limiting membrane contains electron dense particles (B), which can be identified as iron particles from their characteristic crystal structure (D). Original magnifications are $\times 4,000(A), \times 50,000(B$ and $D)$, and $\times 6,000(C)$.

protein excretion and a decrease in creatinine clearance, a marker of the glomerular filtration rate (GFR). Thus, we next investigated the possible physiologic relevance of the abnormal iron deposition in the kidney induced by angiotensin II. Angiotensin II administration caused an increase in the excretion of urinary protein and $\mathrm{N}$-acetyl- $\beta$-D-glucosaminidase (NAG), an indicator of tubular damage, and a decrease in creatinine clearance level. Treating the angiotensin IIinfused rats with DFO blocked the increase in the excretion of urinary protein and NAG but not the decrease in creatinine clearance level (Table 2).

\section{Effect of Antihypertensive Drugs on Angiotensin II-Induced Iron Deposition in the Kidney}

We investigated whether the observed iron deposition and ferritin up-regulation in the tubular epithelial cells were pressor-dependent events. Angiotensin IIinfused rats were given either the nonspecific vasodilator, hydralazine, or the $\mathrm{AT}_{1}$ receptor-specific antagonist, losartan; both of these drugs have been shown to block hypertensive effects of angiotensin II effectively (Aizawa et al, 2000). As we previously reported, both antihypertensive agents suppressed angiotensin II-induced cardiac injury manifested by the loss of cardiomyocytes, fibrous deposition, and inflammatory cell migration (Fig. 6A, a to c). Quantitative assessment of the cardiac injury in angiotensin II-infused rats has been previously reported (Ishizaka et al, 2000). We found that both antihypertensive drugs inhibited iron deposition (Fig. 6A, $d$ to $f$ ) and ferritin up-regulation
(Fig. 6B) in the kidneys of angiotensin Il-infused rats. Therefore, elevation of blood pressure seems to be a critical factor in the observed deposition of iron, which may indicate that intrarenal iron deposition and ferritin induction is a systemic consequence of angiotensin II administration.

\section{Effect of Angiotensin II on Ferritin Expression in Cultured Proximal Renal Tubular Cells}

Finally, we examined whether ferritin expression was regulated by angiotensin $\|$ in cultured rat proximal tubular epithelial cells (IRPTCs). IRPTCs were stimulated with $100 \mathrm{nmol} / \mathrm{L}$ angiotensin II for 4, 8, or 24 hours. Ferritin expression was not significantly altered by angiotensin II administration, consistent with the idea that angiotensin II does not directly regulate the expression of ferritin in tubular epithelial cells.

\section{Discussion}

Here we have demonstrated that chronic angiotensin II administration causes muscle injury and deposition of iron in the lysosomes of proximal tubular epithelial cells. Immunologic analysis revealed that robust ferritin induction was seen in the tubular epithelial cells together with deposits of iron. By treating the angiotensin II-infused rats with the iron chelator DFO, both iron deposition and ferritin induction were inhibited in tubular cells. In addition, DFO also inhibited the angiotensin II-induced increase in the urinary excretion of protein and NAG. Our data point to the possible involvement of abnormal accumulation of iron in the development of angiotensin II-induced renal injury.

We hypothesized that abnormal iron accumulation would occur in rats undergoing continuous angiotensin II administration because of the similarity of two animal models: a rat model of angiotensin II administration (Aizawa et al, 2000) and a rat model of heme protein overload (Nath et al, 2001). In both models, $\mathrm{HO}-1$ is induced in tubular epithelial cells and may have a role in ameliorating renal injury induced by angiotensin II or heme protein overload. In the latter model, Nath et al (2001) have shown that the abnormal iron deposits occur in renal tubular cells. Indeed, abnormal iron deposits were seen in the tubular epithelial cells in rats after angiotensin II infusion. Because treating the angiotensin II-infused rats with $\mathrm{HO}$ inhibitor did not block iron deposition, the induction of HO-1 may not be critical for the iron deposition in these cells.

Two principal questions arise from these results. First, what is the mechanism of iron deposition after angiotensin II infusion? Laboratory data showed an increase in the plasma levels of intracellular enzymes (CK, LDH), suggesting that there was muscle injury. We further showed that the level of CTnT was elevated after angiotensin II infusion, indicating that cardiac injury had also occurred. These observations were supported by histologic analysis (Fig. 6A). However, these data did not exclude the possibility of injury to the skeletal muscles. In addition, it is possible that 
Table 1. Changes in Hemodynamic Variables and Laboratory Data after Angiotensin II Administration

\begin{tabular}{ccccccccc}
\hline & $\begin{array}{c}\text { Systolic blood } \\
\text { pressure } \\
\text { Group }\end{array}$ & $\begin{array}{c}\text { Heat rate } \\
(\mathrm{mmHg})\end{array}$ & $\begin{array}{c}\text { Plasma iron } \\
(\mu \mathrm{ppm})\end{array}$ & $\begin{array}{c}\text { Plasma LDH } / \mathrm{L}) \\
(\mathrm{U} / \mathrm{L})\end{array}$ & $\begin{array}{c}\text { Plasma creatine } \\
\text { kinase } \\
(\mathrm{U} / \mathrm{L})\end{array}$ & $\begin{array}{c}\text { Blood RBC } \\
\left(\times 10^{4} / \mathrm{mm}^{3}\right)\end{array}$ & $\begin{array}{c}\text { Blood hemoglobin } \\
(\mathrm{g} / \mathrm{dll})\end{array}$ & $\begin{array}{r}\text { Hematocrit } \\
(\%)\end{array}$ \\
\hline Control $(\mathrm{n}=5)$ & $131 \pm 3$ & $337 \pm 15$ & $19 \pm 4$ & $154 \pm 31$ & $129 \pm 18$ & $735 \pm 27$ & $15.9 \pm 0.2$ & $51.0 \pm 1.0$ \\
ANG II Day 3 $(\mathrm{n}=4)$ & $174 \pm 3^{\dagger}$ & $391 \pm 10^{\dagger}$ & $23 \pm 1^{\star}$ & $231 \pm 36^{*}$ & $156 \pm 24$ & $812 \pm 26^{\dagger}$ & $17.2 \pm 0.4^{\dagger}$ & $\mathrm{n} . \mathrm{t}$. \\
ANG II Day 7 $(\mathrm{n}=6)$ & $192 \pm 4^{\dagger}$ & $420 \pm 29^{\dagger}$ & $40 \pm 9^{\dagger}$ & $529 \pm 113^{\dagger}$ & $315 \pm 51^{\dagger}$ & $785 \pm 44$ & $15.8 \pm 0.5$ & $51.2 \pm 2.2$ \\
\hline
\end{tabular}

ANG II and n.t. indicate angiotensin II and not tested, respectively.

${ }^{\star} p<0.05$ and ${ }^{\dagger} p<0.01$ versus control levels.

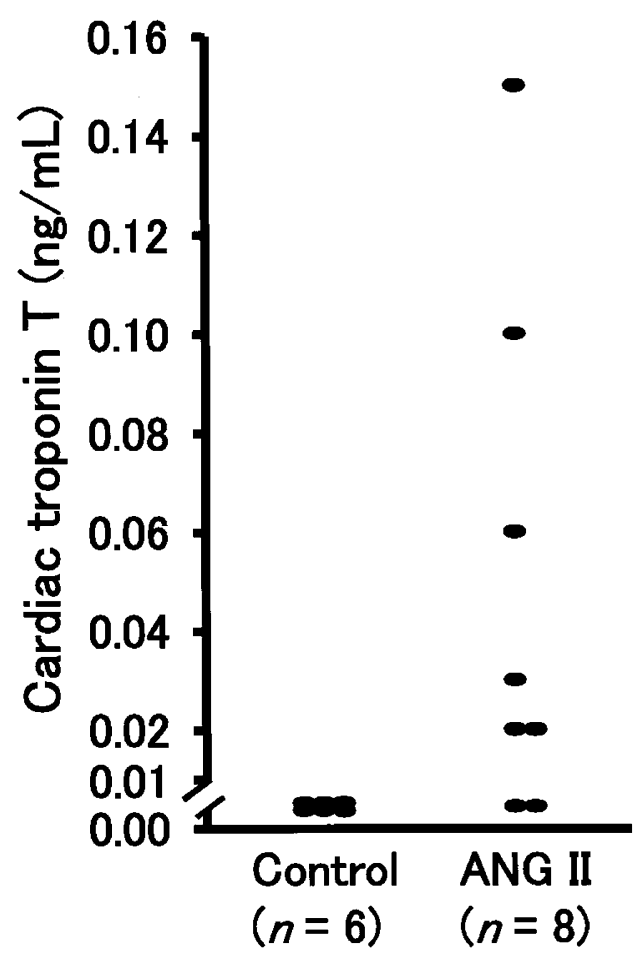

Figure 3.

Cardiac injury detected as an increase in cardiac troponin T (CTnT) of more than $0.01 \mathrm{ng} / \mathrm{ml}$. All the plasma CTnT levels from the control rats were below the detection limit of the assay. Angiotensin II administration for 7 days apparently increased the plasma CTnT levels, indicating the presence of injury to the cardiomyocytes.

angiotensin II acted directly on the tubular epithelial cells and altered the iron homeostasis in these cells. To test this possibility, hydralazine was given to angiotensin II-infused rats. We found that hydralazine inhibited the intrarenal iron deposition and ferritin up-regulation induced by angiotensin II. These findings may suggest that the iron deposition in the renal tubular cells cannot be induced by increased levels of circulating angiotensin II alone and, thus, that this phenomenon may be a systemic consequence. It is of note that hydralazine treatment also suppressed angiotensin II-induced cardiac injury (Fig. 7A), further suggesting a possible relationship between muscle injury and iron deposition in the kidney. In addition, we showed that stimulating IRPTCs with angiotensin II did not alter the ferritin expression in these cells, which indicates that angiotensin II does not directly alter ferritin expression in tubular epithelial cells. Using IRPTCs, we are now examining in vitro whether iron uptake and/or iron release from these cells are modulated by angiotensin II stimulation.

Although the mechanism by which angiotensin II causes muscle injury has not been examined in the present study, there are several possibilities. Recent reports showed that both angiotensin II and mechanical stretch increase the production of tumor necrosis factor $\alpha$ (TNF- $\alpha$ ) in cardiac fibroblasts (Yokoyama et al, 1999) and that angiotensin II may be involved in the secretion of TNF- $\alpha$ from skeletal muscle under hypertensive conditions (Togashi et al, 2000). Thus, TNF- $\alpha$ may play a role in the muscle injury induced by angiotensin II and hypertension (Cheng et al, 1992; Garcia-Martinez et al, 1993). Another possibility is that angiotensin II infusion may reduce muscular perfusion by impairing microcirculation and causing the loss of microvessels (Greene, 1998). These possibilities should be clarified in future studies.

Second, what is the physiologic role of the angiotensin II-induced iron deposition in the renal tubular cells? DFO treatment blocked angiotensin II-induced iron deposition in the kidney, and this intervention also completely suppressed the increase in the urinary excretion of protein and NAG. These data suggest that angiotensin II-induced iron deposition in the kidney results in renal tubular injury, possibly by destabilizing the lysosome and by increasing the generation of reactive oxygen species in the tubular cells (Harris et al, 1995). There are several reports assessing the role of iron deposition in the kidney in other animal models and human cases. Nankivell et al (1992) have reported that the extent of iron accumulation in the proximal tubular cells observed in human chronic renal disease correlates with the excretion of urinary proteins but not with GFR. Zhou et al (2000) have reported that chronic experimental hemosiderosis, which causes abnormal iron deposition in the proximal tubular epithelial cells, results in an increase in the urinary protein excretion but does not affect GFR in rats. Interestingly, in the present study, DFO treatment did not inhibit the angiotensin II-induced decrease in creatinine clearance. These findings suggest that iron deposition in the kidney may have a role in the increase in urinary protein excretion but not in the decrease in GFR.

In conclusion, chronic administration of angiotensin II results in the deposition of iron in the proximal tubular epithelial cells, in which expression of ferritin and $\mathrm{HO}-1$ is also increased. The treatment of angiotensin II-infused rats with an iron chelator abolishes iron deposition in these cells and suppresses the 

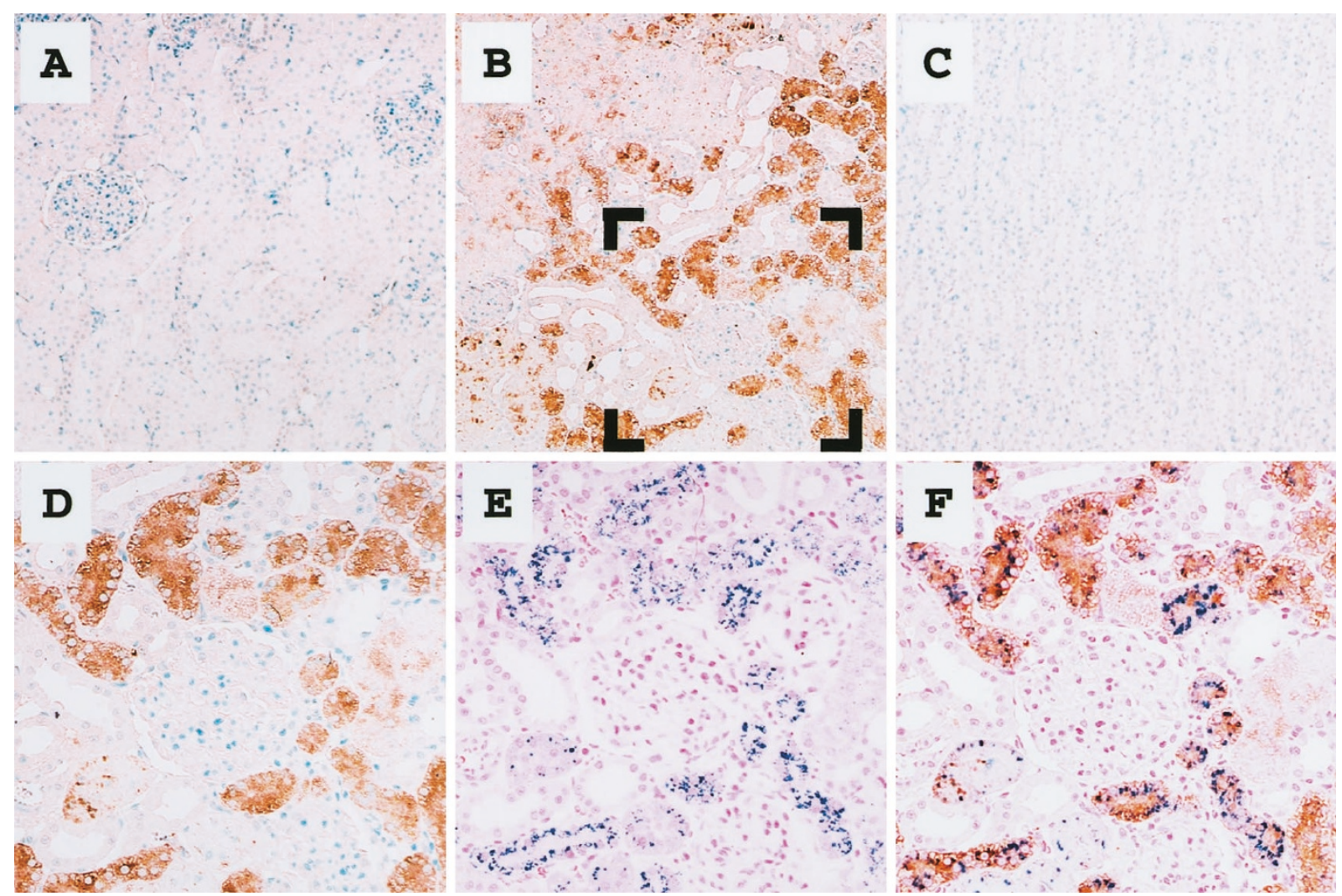

\section{Figure 4.}

Immunohistochemistry of ferritin in the kidney of an angiotensin II-infused rat. A to D, Immunoperoxidase staining of ferritin in the kidney of control rat (A) and in the renal cortex ( $B$ and $D$ ) and medullary regions $(C)$ of the angiotensin II-infused rat. E, Prussian blue staining. D and $E$ are from serial sections. F, Prussian blue and ferritin costaining of a kidney sample from an angiotensin II-infused rat revealed that the tubular epithelial cells that were positive for iron were also positive for ferritin. Original magnifications are $\times 250$ (A to $C)$ and $\times 800$ (D to F).

angiotensin II-induced increase in the urinary excretion of protein and NAG. Our data suggest that abnormal iron deposition in the kidney plays, in part, a causal role in angiotensin Il-induced renal dysfunction.

\section{Materials and Methods}

\section{Animal Models}

The rat angiotensin II hypertension model was induced in male Sprague-Dawley rats (Nippon Bio-Supply Center, Tokyo, Japan) by subcutaneous implantation of an osmotic minipump (Alzet model 2001; Alza Pharmaceutical, Palo Alto, California) as described previously (Ishizaka et al, 1997). Val ${ }^{5}$-angiotensin II (Sigma Chemical Company, St. Louis, Missouri) was infused at a rate of $0.7 \mathrm{mg} / \mathrm{kg} /$ day for up to 7 days. Hemodynamic variables were measured in conscious rats by tail-cuff plethysmography (UR-5000; Ueda Seisakusyo, Tokyo, Japan). Some rats were subjected to daily intraperitoneal injections of the $\mathrm{HO}-1$ inhibitor zinc protoporphyrin (Porphyrin Products, Logan, Utah) at a dose of $50 \mathrm{~mol} / \mathrm{kg} /$ day, which was started 2 days before pump implantation and continued until death. To test the pressor dependency of the angiotensin Il-induced events, some rats were given the nonspecific vasodilator, hydralazine $(15 \mathrm{mg} / \mathrm{kg} /$ day; Sigma Chemical) or the selective $\mathrm{AT}_{1}$ receptor antagonist, losartan (25 mg/kg/day; a kind gift from Merck, Rahway, New Jersey) in the drinking water, beginning 2 days before pump implantation and continuing

Table 2. Effect of the Iron Chelator on Angiotensin II-Induced Renal Injury

\begin{tabular}{|c|c|c|c|c|c|c|}
\hline Group & $\begin{array}{l}\text { Systolic blood } \\
\text { pressure } \\
(\mathrm{mmHg})\end{array}$ & $\begin{array}{l}\text { Heat rate } \\
\text { (ppm) }\end{array}$ & $\begin{array}{c}\text { Iron } \\
(\mu \mathrm{mol} / \mathrm{L})\end{array}$ & $\begin{array}{l}\text { Creatinine clearance } \\
\qquad(\mathrm{mL} / \mathrm{min})\end{array}$ & $\begin{array}{l}\text { Urinary NAG } \\
\qquad(\mathrm{U} / \mathrm{g} \mathrm{Cr})\end{array}$ & $\begin{array}{l}\text { Urinary protein } \\
\text { (mg/24 hrs) }\end{array}$ \\
\hline Control $(n=5)$ & $131 \pm 3^{\dagger}$ & $337 \pm 15^{\dagger}$ & $19 \pm 4^{\dagger}$ & $3.2 \pm 0.2^{\dagger}$ & $32.9 \pm 2.7^{\dagger}$ & $9.7 \pm 1.3^{\dagger}$ \\
\hline ANG $\|(n=6)$ & $192 \pm 4^{\star}$ & $420 \pm 29^{\star}$ & $40 \pm 9^{\star}$ & $1.2 \pm 0.2^{\star}$ & $68.4 \pm 7.8^{\star}$ & $28.1 \pm 7.2^{\star}$ \\
\hline DFO $(n=6)$ & $134 \pm 3^{\dagger}$ & $330 \pm 25^{\dagger}$ & $20 \pm 3^{\dagger}$ & $3.0 \pm 0.3^{\dagger}$ & $26.6 \pm 1.5^{\dagger}$ & $4.3 \pm 0.6^{\star \dagger}$ \\
\hline ANG II + DFO $(n=6)$ & $198 \pm 7^{\star}$ & $423 \pm 35^{\star}$ & $19 \pm 2^{\dagger}$ & $1.2 \pm 0.2^{\star}$ & $26.8 \pm 3.4^{\dagger}$ & $9.5 \pm 2.3^{\dagger}$ \\
\hline
\end{tabular}

ANG II and DFO indicate angiotensin II and deferoxamine, respectively.

${ }^{*} p<0.01$ versus control and ${ }^{\dagger} p<0.01$ versus ANG II group. 
A

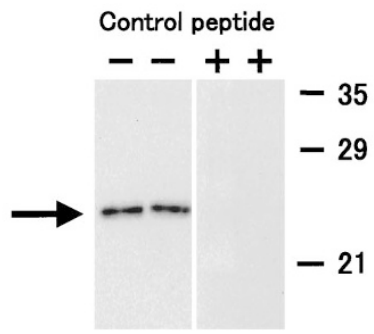

B
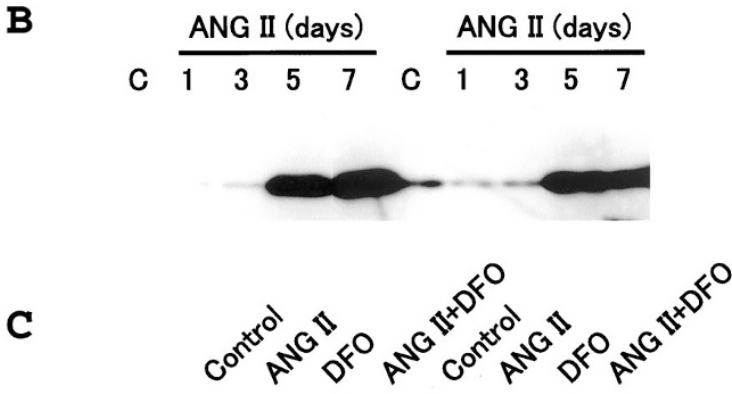

Ferritin
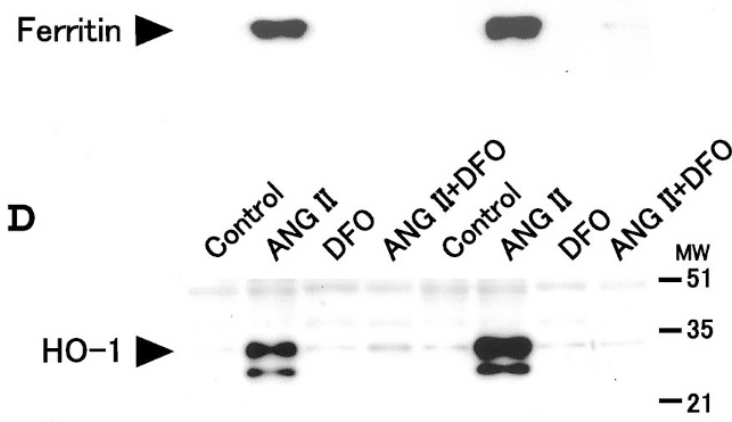

Figure 5.

Effects of angiotensin II and the iron chelator, deferoxamine (DFO), on ferritin expression in the kidney. A. Specificity of the anti-ferritin antibody. In the left-hand lanes, anti-rat ferritin antibody detected a single band at the size of $\sim 25 \mathrm{kd}$ (arrow). In the right-hand lanes, immunizing peptide, ie, rat liver ferritin $(10 \mu \mathrm{g} / \mathrm{L})$, was preincubated with the primary antibody for 1 hour. B, Time course of renal ferritin expression after angiotensin II infusion. Angiotensin II infusion for 5 days or more resulted in a robust increase in expression of ferritin protein. C, Effect of DFO on the angiotensin II-induced up-regulation of ferritin. D, Effect of DFO on angiotensin II-induced HO-1 induction. In B to D, representative results from four to six animals in each group are shown.

throughout angiotensin II infusion. To test the effect of iron chelation, rats were given daily subcutaneous injections of the iron chelator, DFO (a kind gift from Novartis, Basel, Switzerland) at a dose of $6 \mathrm{mg} / \mathrm{kg} /$ day, beginning 2 days before pump implantation and continuing until death.

\section{Protein Purification and Immunoblot Analysis}

Protein was isolated by homogenizing samples in the lysis buffer $(50 \mathrm{mmol} / \mathrm{L}$ HEPES, $5 \mathrm{mmol} / \mathrm{L}$ EDTA, and $50 \mathrm{mmol} / \mathrm{L} \mathrm{NaCl}$; $\mathrm{pH}$ 7.5) containing protease inhibitors $(10 \mu \mathrm{g} / \mathrm{ml}$ aprotinin, $1 \mathrm{mmol} / \mathrm{L} \mathrm{PMSF}$, and 10 $\mu \mathrm{g} / \mathrm{mL}$ leupeptin). Polyclonal antibodies against rat HO-1 (SPA895; StressGen, Victoria, British Columbia, Canada] and rat ferritin (Panapharm, Kumamoto, Japan) were used at a 1:2000 dilution, and horseradish peroxidase-conjugated secondary antibody (Jackson
ImmunoResearch, West Grove, Pennsylvania) was used at a 1:2000 dilution. The ECL Western blotting system (Amersham Life Sciences, Arlington Heights, Illinois) was used for detection. Band intensity was calculated using the image analysis software, $\mathrm{NIH}$ Image analysis software (National Institutes of Health, Research Service Branch, Bethesda, Maryland) and was expressed as a percentage of the control value.

\section{Histologic and Immunohistochemical Analyses}

Prussian blue and Turnbull's blue staining was used to detect iron deposition. Immunohistochemistry was performed as described previously (Aizawa et al, 1999). Briefly, deparaffinized sections were preincubated with $10 \%$ horse serum. Sections were then incubated with the polyclonal antibody against rat $\mathrm{HO}-1$ or rat ferritin at a 1:200 dilution at $37^{\circ} \mathrm{C}$ for 1 hour. In some experiments, after staining of either $\mathrm{HO}-1$ or ferritin, the same section was additionally stained with Prussian blue to investigate the colocalization of iron deposition and HO-1 or ferritin.

\section{Tissue Preparation for Electron Microscopy}

For electron microscopy, kidney samples were fixed in $2.5 \%$ glutaraldehyde, fixed in $1 \%$ osmium tetroxide, and dehydrated in a graded alcohol series. The samples were then embedded in Epon. Ultra thin sections were stained with uranyl acetate and lead citrate and examined with a transmission electron microscope (JEM 1200 EX; JEOL, Tokyo, Japan).

\section{Assay of Creatinine, Protein, and N-Acetyl- $\beta-\mathrm{D}-$ Glucosaminidase in the Urine}

A urine sample was collected 24 hours before death. Plasma and urine creatinine concentrations were measured with the Jaffe reaction, and urinary protein was measured by the pyrogallol red-molybdate protein dyebinding method (SRL, Tokyo, Japan). Concentrations of urinary excretions of NAG, an indicator of tubular damage (Bosomworth et al, 1999), were determined using sodio-3,3'-dichlorophenolsulfonphthaleinyl $\mathrm{N}$-acetyl- $\beta$ D-glucosaminide as a substrate (Shionogi, Osaka, Japan). Urinary concentrations of NAG were normalized to urine creatinine levels.

\section{Assessment of Plasma Iron Levels and Markers of Muscle Injury}

Iron was measured by the Nitroso-PSAP method. Muscle injury was assessed by measuring $\mathrm{CK}$ and LDH levels by the Wroblewski-KaDue method and a standard CK-NAC test, respectively (SRL) in plasma from venous blood samples. In addition, cardiac injury was assessed by measuring CTnT levels by electrochemiluminescence immunoassay with a lower detection limit of $0.01 \mathrm{ng} / \mathrm{mL}(\mathrm{SRL})$. 
A
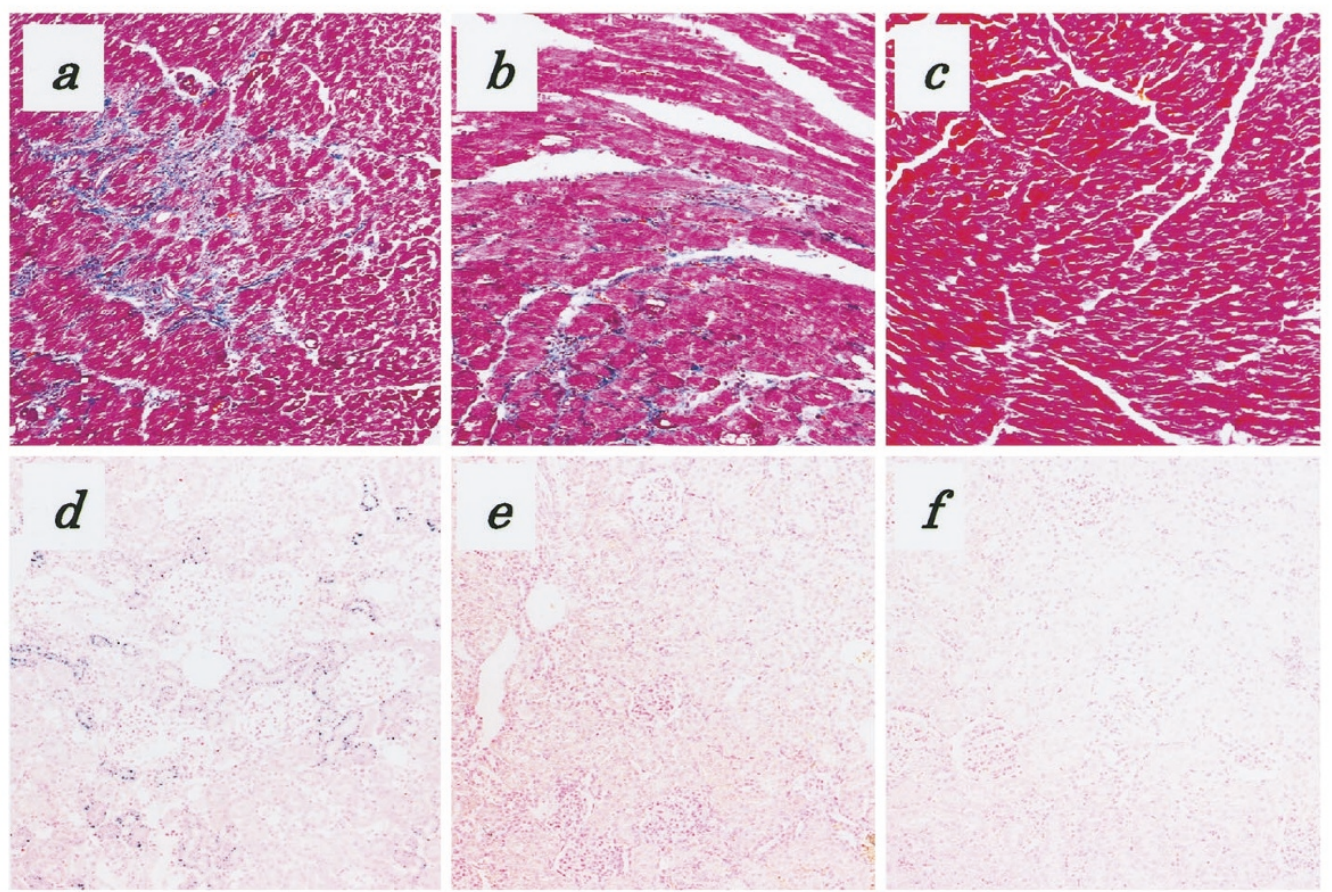

$\mathbf{B}$
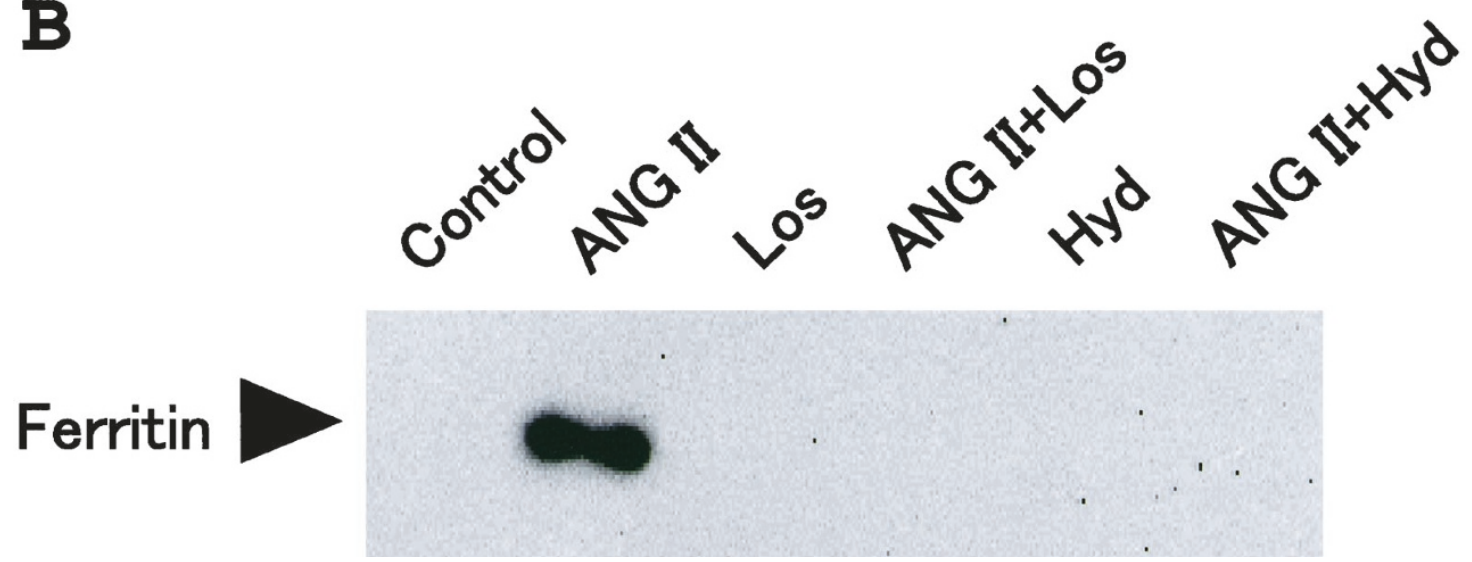

Figure 6.

Effect of hydralazine and losartan on cardiac injury, iron deposition in the kidney, and renal ferritin expression induced by angiotensin II administration. A, Angiotensin II was infused at a rate of $0.7 \mathrm{mg} / \mathrm{kg} /$ day for 7 days ( $a$ to $f$ ). Rats were given the nonspecific vasodilator, hydralazine (Hyd; $b$ and $e$ ), or the specific AT ${ }_{1}$ receptor inhibitor, losartan ( $c$ and $f)$. Masson's trichrome staining of the heart $(a$ to $c)$ and Prussian blue staining of the kidney ( $d$ to $f$ ) are shown. Note that both antihypertensive drugs could suppress the cardiac injury and iron deposition induced by angiotensin II in tubular epithelial cells. B, Effect of hydralazine and losartan on the angiotensin II-induced up-regulation of ferritin protein.

\section{Culture of Transformed Rat Proximal Tubular Cells}

Culture of established rat proximal tubular cells, IRPTCs, was performed as described previously (Ingelfinger et al, 1999). Cells were cultured in DMEM with $5 \%$ fetal calf serum. Cultures were supplemented with $3.8 \mathrm{mg} / \mathrm{mL} \mathrm{NaHCO}$, $25 \mathrm{mmol} / \mathrm{L}$ HEPES buffer (pH 7.5), $0.1 \mathrm{mmol} / \mathrm{L}$ sodium pyruvate, $100 \mathrm{U} / \mathrm{mL}$ penicillin, $100 \mu \mathrm{g} / \mathrm{mL}$ streptomycin, and $0.01 \mathrm{mmol} / \mathrm{L}$ nonessential amino acids.

\section{Statistical Analysis}

Data are expressed as the mean \pm SEM. We used ANOVA followed by a multiple comparison test for comparisons on initial data, before expressing results 
A

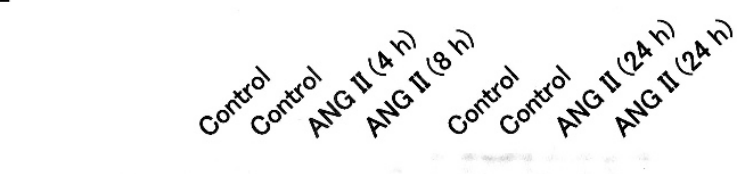

Ferritin

B
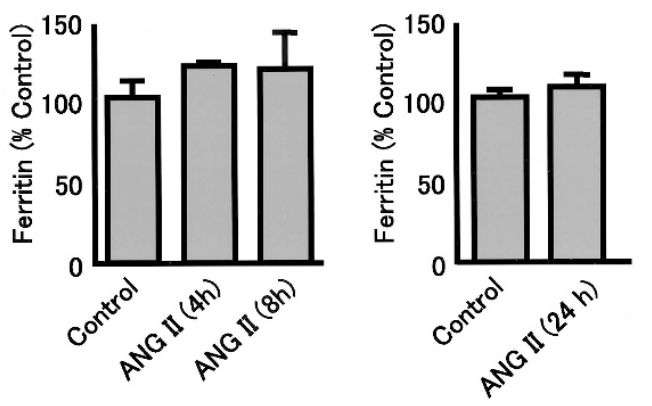

Figure 7.

Ferritin expression in the cultured renal tubular cells (IRPTCs). Cultured renal tubular epithelial cells (IRPTCs) were stimulated with angiotensin II (ANG II, $100 \mathrm{nmol} / \mathrm{L}$ ) for 4,8 , or 24 hours and the ferritin protein expression was analyzed. A, Representative immunoblot. B, Bar graph summarizing data from four to eight independent experiments.

as a percentage of the control value. A value of $p<$ 0.05 was considered to be statistically significant.

\section{Acknowledgements}

We are highly appreciative of Ms. Naoko Amitani for her technical assistance and Dr. Masaomi Nangaku for his constructive comments.

\section{References}

Aizawa T, Ishizaka N, Kurokawa K, Nagai R, Nakajima H, Taguchi J, and Ohno M (2001). Different effects of angiotensin II and catecholamine on renal cell apoptosis and proliferation in rats. Kidney Int 59:645-653.

Aizawa T, Ishizaka N, Taguchi J, Kimura S, Kurokawa K, and Ohno M (1999). Balloon injury does not induce heme oxygenase-1 expression, but administration of hemin inhibits neointimal formation in balloon-injured rat carotid artery. Biochem Biophys Res Commun 261:302-307.

Aizawa T, Ishizaka N, Taguchi J, Nagai R, Mori I, Tang SS, Ingelfinger JR, and Ohno M (2000). Heme oxygenase-1 is upregulated in the kidney of angiotensin II-induced hypertensive rats: possible role in renoprotection. Hypertension 35 : 800-806.

Alfrey AC, Froment DH, and Hammond WS (1989). Role of iron in the tubulo-interstitial injury in nephrotoxic serum nephritis. Kidney Int 36:753-759.

Bosomworth MP, Aparicio SR, and Hay AW (1999). Urine $\mathrm{N}$-acetyl-beta-D-glucosaminidase: A marker of tubular damage? Nephrol Dial Transplant 14:620-626.

Cheng J, Turksen K, Yu QC, Schreiber H, Teng M, and Fuchs E (1992). Cachexia and graft-vs.-host-disease-type skin changes in keratin promoter-driven TNF alpha transgenic mice. Genes Dev 6:1444-1456.

Ferris CD, Jaffrey SR, Sawa A, Takahashi M, Brady SD, Barrow RK, Tysoe SA, Wolosker H, Baranano DE, Dore S, Poss KD, Snyder SH (1999). Haem oxygenase-1 prevents cell death by regulating cellular iron. Nat Cell Biol 1:152-157.

Garcia-Martinez C, Lopez-Soriano FJ, and Argiles JM (1993). Acute treatment with tumour necrosis factor-alpha induces changes in protein metabolism in rat skeletal muscle. Mol Cell Biochem 125:11-18.

Greene AS (1998). Life and death in the microcirculation: A role for angiotensin II. Microcirculation 5:101-107.

Harris DC, Tay YC, Chen J, Chen L, and Nankivell BJ (1995). Mechanisms of iron-induced proximal tubule injury in rat remnant kidney. Am J Physiol 269:F218-F224.

Ingelfinger JR, Jung F, Diamant D, Haveran L, Lee E, Brem A, and Tang SS (1999). Rat proximal tubule cell line transformed with origin-defective SV40 DNA: Autocrine ANG II feedback. Am J Physiol 276:F218-F227.

Ishizaka N, Aizawa T, Mori I, Taguchi J, Yazaki Y, Nagai R, and Ohno M (2000). Heme oxygenase-1 is upregulated in the rat heart in response to chronic administration of angiotensin II. Am J Physiol Heart Circ Physiol 279:H672-H678.

Ishizaka N, de Leon H, Laursen JB, Fukui T, Wilcox JN, De Keulenaer G, Griendling KK, and Alexander RW (1997). Angiotensin II-induced hypertension increases heme oxygenase-1 expression in rat aorta. Circulation 96:1923-1929.

Kawabata T, Ma Y, Yamador I, and Okada S (1997). Ironinduced apoptosis in mouse renal proximal tubules after an injection of a renal carcinogen, iron-nitrilotriacetate. Carcinogenesis 18:1389-1394.

Nankivell BJ, Boadle RA, and Harris DC (1992). Iron accumulation in human chronic renal disease. Am J Kidney Dis 20:580-584.

Nath KA, Balla G, Vercellotti GM, Balla J, Jacob HS, Levitt MD, and Rosenberg ME (1992). Induction of heme oxygenase is a rapid, protective response in rhabdomyolysis in the rat. J Clin Invest 90:267-270.

Nath KA, Vercellotti GM, Grande JP, Miyoshi H, Paya CV, Manivel JC, Haggard JJ, Croatt AJ, Payne WD, and Alam J (2001). Heme protein-induced chronic renal inflammation: Suppressive effect of induced heme oxygenase-1. Kidney Int 59:106-117.

Ohta K, Yachie A, Fujimoto K, Kaneda H, Wada T, Toma T, Seno A, Kasahara Y, Yokoyama H, Seki H, and Koizumi S (2000). Tubular injury as a cardinal pathologic feature in human heme oxygenase-1 deficiency. Am J Kidney Dis 35:863-870.

Paller MS and Hedlund BE (1988). Role of iron in postischemic renal injury in the rat. Kidney Int 34:474-480.

Poss KD and Tonegawa S (1997). Heme oxygenase 1 is required for mammalian iron reutilization. Proc Natl Acad Sci USA 94:10919-10924.

Stocker R, Yamamoto Y, McDonagh AF, Glazer AN, and Ames BN (1987). Bilirubin is an antioxidant of possible physiological importance. Science 235:1043-1046.

Togashi N, Ura N, Higashiura K, Murakami H, and Shimamoto K (2000). The contribution of skeletal muscle tumor necrosis factor-alpha to insulin resistance and hypertension in fructose-fed rats. J Hypertens 18:1605-1610. 
Vile GF and Tyrrell RM (1993). Oxidative stress resulting from ultraviolet $A$ irradiation of human skin fibroblasts leads to a heme oxygenase-dependent increase in ferritin. $\mathrm{J}$ Biol Chem 268:14678-14681.

Vogt BA, Alam J, Croatt AJ, Vercellotti GM, and Nath KA (1995). Acquired resistance to acute oxidative stress: Possible role of heme oxygenase and ferritin. Lab Invest 72:474483.

Yokoyama T, Sekiguchi K, Tanaka T, Tomaru K, Arai M, Suzuki T, and Nagai R (1999). Angiotensin II and mechanical stretch induce production of tumor necrosis factor in cardiac fibroblasts. Am J Physiol 276:H1968-1976.
Zainal TA, Weindruch R, Szweda LI, and Oberley TD (1999). Localization of 4-hydroxy-2-nonenal-modified proteins in kidney following iron overload. Free Radic Biol Med 26:11811193.

Zhou XJ, Laszik Z, Wang XQ, Silva FG, and Vaziri ND (2000). Association of renal injury with increased oxygen free radical activity and altered nitric oxide metabolism in chronic experimental hemosiderosis. Lab Invest 80(1905)-1914.

Zhou XJ, Vaziri ND, Pandian D, Wang ZQ, Mazowiecki M, Liao SY, and Oveisi $F$ (1996). Urinary concentrating defect in experimental hemochromatosis. J Am Soc Nephrol 7:128134. 